\title{
Oxytocin Reverses Amphetamine-Induced Deficits in Social Bonding: Evidence for an Interaction with Nucleus Accumbens Dopamine
}

\author{
Kimberly A. Young, Yan Liu, Kyle L. Gobrogge, Hui Wang, and Zuoxin Wang \\ Department of Psychology, Program in Neuroscience, Florida State University, Tallahassee, Florida 32306
}

\begin{abstract}
Drug addiction has devastating consequences on social behaviors and can lead to the impairment of social bonding. Accumulating evidence indicates that alterations in oxytocin (OT) and dopamine (DA) neurotransmission within brain reward circuitry may be involved. We investigated this possibility, as well as the therapeutic potential of OT for drug-induced social deficits, using the prairie vole (Microtus ochrogaster) - a socially monogamous rodent that forms enduring pair bonds between adult mates. We demonstrate that repeated exposure to the commonly abused psychostimulant amphetamine (AMPH) inhibits the formation of partner preferences (an index of pair bonding) in female prairie voles. AMPH exposure also altered $\mathrm{OT}$ and DA neurotransmission in regions that mediate partner preference formation: it decreased $\mathrm{OT}$ and $\mathrm{DA} \mathrm{D}_{2}$ receptor immunoreactivity in the medial prefrontal cortex (mPFC) and nucleus accumbens (NAcc), respectively, and increased NAcc DA levels. Administration of OT directly into the mPFC of AMPH-exposed voles restored partner preferences, and altered NAcc DA levels, and this effect was dependent on OT receptor activation. Together, these data suggest that repeated AMPH exposure impairs pair bonding through an OT-mediated mechanism, and that OT and DA systems within brain reward circuitry may interact to mediate the complex relationship between drug abuse and social bonding. Further, these results provide empirical support for the idea that the central OT system may represent an important target for the treatment of social deficits in addiction.
\end{abstract}

Key words: addiction; amphetamine; dopamine; oxytocin; social bonding

\section{Introduction}

Drug addiction has devastating consequences on human relationships and is associated with impairments in the most fundamental of social behaviors (Strathearn and Mayes, 2010; Young et al., 2011a)—including the formation and maintenance of selective attachments between mother and child (i.e., maternal bonds) and mating partners (i.e., pair bonds). The costs of such deficits are profound, and include high rates of child neglect and abuse (Wasserman and Leventhal, 1993), a decreased likelihood of marriage, and an accelerated rate of separation/divorce (Kaestner, 1995; Collins et al., 2007) in addicted individuals. This is particularly disquieting when one considers the cross-cultural benefits of social bonding on physical and psychological health (House et al., 1988; Kiecolt-Glaser and Newton, 2001).

Received Oct. 6, 2013; revised April 8, 2014; accepted May 14, 2014.

Author contributions: K.A.Y. and Z.W. designed research; K.A.Y., Y.L., and H.W. performed research; K.A.Y., K.L.G., and H.W. analyzed data; K.A.Y. and Z.W. wrote the paper.

This work was supported by National Institutes of Health Grants DA25570 to K.A.Y.; and DA19627, DA23048, and MH58616 to Z.W. We thank Dr. Claudia Lieberwirth, Dr. Adam Smith, and Kelly Lei for their comments on the manuscript. We also especially thank Dr. Maurizio Tomaiuolo for his helpful discussions.

The authors declare no competing financial interests.

Correspondence should be addressed to Kimberly A. Young, Perelman School of Medicine, Department of Psychiatry, University of Pennsylvania, 3900 Chestnut Street, Philadelphia, PA 19104, E-mail: kiyo@mail.med.upenn.edu, and Zuoxin Wang, Department of Psychology, Program in Neuroscience, Florida State University, 1107 West Call Street, Tallahassee, FL 32306, E-mail: zwang@psy.fsu.edu.

DOI:10.1523/JNEUROSCI.4275-13.2014

Copyright $\odot 2014$ the authors $\quad 0270-6474 / 14 / 348499-08 \$ 15.00 / 0$
Accumulating evidence indicates that the mesocorticolimbic dopamine (DA) system is likely involved in the effects of drugs of abuse on social bonding. DA neurotransmission within this circuit [e.g., nucleus accumbens (NAcc), ventral tegmental area (VTA), and medial prefrontal cortex (mPFC)] not only plays a critical role in social bonding (Gingrich et al., 2000; Aragona et al., 2006), but undergoes significant neuroadaptations [i.e., altered DA release and DA receptor (DAR) expression/sensitivity] as a result of drug exposure (Henry et al., 1989; Nestler, 2005). Further, such neuroadaptations are becoming progressively linked with modified sociobehavioral output (Clemens et al., 2004; Febo and Ferris, 2007; Liu et al., 2010).

Less recognized, however, is that drug-induced alterations in mesocorticolimbic oxytocin (OT) neurotransmission may also play a role (McGregor et al., 2008). This endogenous neuropeptide regulates related social behaviors (Melis and Argiolas, 2011), and through its actions in the NAcc, VTA, and MPFC- and interactions with accumbal DA- directly mediates the formation and maintenance of social bonds (Young et al., 2001; Liu and Wang, 2003; Ross et al., 2009b; Bosch and Neumann, 2012). Importantly, changes in markers of OT function following drug exposure within these and functionally related brain regions have been increasingly reported (Sarnyai et al., 1992; Johns et al., 1997b; Butovsky et al., 2006). While these effects vary by drug type and dosing regimen, they indicate that alterations in OT systems may also contribute to the effects of drugs of abuse on 
social bonding. Further, they highlight the possibility that the OT system might represent an important target for the treatment of social deficits in addiction.

To investigate this possibility, we examined the effects of a commonly abused psychostimulant, amphetamine (AMPH), on pair bonding in the socially monogamous female prairie vole (Mictrotus ochragaster), and the involvement of mesocorticolimbic OT and DA in these effects. Given the critical role of OT and DA in pair bond formation (for review, see Young et al., 2011b) and the evidence to suggest that these systems are altered by drugs of abuse, we hypothesized that repeated AMPH exposure impairs pair bonding in females and that alterations in OT and DA neurotransmission in the NAcc, VTA, and/or mPFC underlie this effect. Additionally, to directly test the potential therapeutic benefit of OT for drug-induced social deficits, we evaluated the effects of OT administration on pair bonding in AMPH-exposed voles.

\section{Materials and Methods}

Subject animals. Subjects were sexually naive female prairie voles $(M$. ochrogaster) from a laboratory breeding colony descended from populations in southern Illinois. Subjects were weaned at $\sim 21 \mathrm{~d}$ of age and then housed in same-sex pairs in plastic cages $(29 \times 18 \times 13 \mathrm{~cm})$ that contained cedar chip bedding on a $14 / 10 \mathrm{~h}$ light/dark cycle and at a room temperature of $\sim 20^{\circ} \mathrm{C}$. Food and water were available ad libitum. Subjects were 90-140 d of age when tested. For manipulations that required mating, nonrelated sexually experienced conspecific males were used as stimulus animals. All experiments were conducted in accordance with the guidelines of the Institutional Care and Use Committee at Florida State University.

Drugs. D-AMPH sulfate (Sigma) was dissolved in saline and delivered via intraperitoneal injection $(0.1 \mathrm{ml} / 40 \mathrm{~g}$ body weight $)$. Estrogen benzoate $(\mathrm{EB} ; 20 \mu \mathrm{g} / \mathrm{ml})$ was dissolved in sesame oil and delivered via subcutaneous injection $(0.1 \mathrm{ml} / 40 \mathrm{~g}$ body weight $)$. OT ( $1 \mathrm{ng} / 200 \mathrm{~nL}$; Peninsula Laboratory) and an OT receptor (OTR) antagonist (OTA; $10 \mathrm{ng}$ or 200 ng/200 nL; [d(CH2)5, Tyr(Me)2, Thr4, Tyr-NH29]-OVT; Peninsula Laboratory) were dissolved in artificial CSF and delivered site specifically into the prelimbic cortex (PLC) via microinjection. OTA has been demonstrated to be a high-affinity selective OTA in a number of rodent species, including prairie voles (Witt et al., 1991).

$24 \mathrm{~h}$ cohabitation. Subjects and stimulus males were placed into a clean cage with food and water, and were allowed to freely interact. Behavioral interactions were videotaped, and later used for the verification and quantification of mating.

Partner preference test. Preferences for a familiar partner versus an unfamiliar stranger were examined using a $3 \mathrm{~h}$ partner preference (PP) test, as previously described (Liu and Wang, 2003). Briefly, the testing apparatus consisted of a central cage connected by hollow tubes to two identical cages, each containing a stimulus male- either the familiar animal with which the subject had been previously housed (partner) or an unfamiliar conspecific animal (stranger). Stimulus males were loosely tethered within their separate cages. At the start of the test, the subject was placed into the central cage and allowed to move freely throughout the testing apparatus. Photobeam light sensors placed over the hollow tubes recorded the frequency of cage entries. Behavioral interactions during the test were videotaped and later quantified.

Western blot. Brains were sectioned at a width of $\sim 300 \mu \mathrm{m}$ at -12 to $-15^{\circ} \mathrm{C}$. Tissue punches from the NAcc (punches included both core and shell subregions), mPFC (punches included the PLC and infralimbic cortex), and VTA from each subject were individually sonicated and centrifuged in RIPA extraction buffer, pH 7.4, containing, $10 \mathrm{~mm}$ Trizma base, $150 \mathrm{~mm} \mathrm{NaCl}, 1 \mathrm{~mm}$ EDTA, 0.1\% SDS, 1\% Triton X-100, and 1\% sodium deoxycholate. Total protein in each sample was measured using a DC protein assay (catalog \#500-0112, Bio-Rad). After adding loading buffer from a stock solution consisting of $1 \mathrm{~g}$ of SDS, $12 \mathrm{ml}$ of glycerol, 8 $\mathrm{ml}$ of $1.0 \mathrm{~mm}$ Tris- $\mathrm{HCl}, \mathrm{pH} 6.8$, bromophenol blue, and $2 \mathrm{ml}$ of $\beta$-mercapatoethanol, $20 \mu \mathrm{g}$ of protein was loaded into wells. Each well contained protein from a single subject, and control and treatment samples were loaded in an alternating order to ensure that samples from each treatment group were evenly distributed throughout the gel. Protein was electrophoresed on precast $10 \%$ acrylamide gels, using $1 \times$ Tris glycine SDS (catalog \#1610772, Bio-Rad) as a running buffer (catalog \#161-0772, Bio-Rad). Protein was transferred to a PVDF membrane at $4^{\circ} \mathrm{C}$ using a buffer that consisted of $80 \% 1 \times$ Tris glycine (catalog \#BP13064, Fisher Scientific) and 20\% methanol. For DA receptor immunoreactive labeling, PVDF membranes were then blocked in Tris-buffered saline (TBS) with $0.1 \%$ Tween 20 (TBS-T) and $5 \%$ nonfat milk for $1 \mathrm{~h}$ at $23^{\circ} \mathrm{C}$. The membrane was then incubated overnight at $4^{\circ} \mathrm{C}$ in TBS-T plus milk containing a 1:1000 concentration of $\mathrm{D}_{2}$ receptor (D2R; H-50) primary antibody (catalog \#sc-9113, Santa Cruz Biotechnology), or a 1:3000 concentration of D1R primary antibody (catalog \#D1897, Sigma). Membranes were then washed for $60 \mathrm{~min}$ at $23^{\circ} \mathrm{C}$ in TBS-T, incubated for $1 \mathrm{~h}$ at a 1:40,000 concentration of peroxidase-labeled secondary antibody, and then washed for $1 \mathrm{~h}$ in $0.1 \%$ TBS-T. For OT receptor immunoreactive labeling, PVDF membranes were blocked in Superblock T20 TBS (catalog \#37536, Thermo Scientific) for $1 \mathrm{~h}$ at $23^{\circ} \mathrm{C}$. The membranes were then incubated overnight at $4^{\circ} \mathrm{C}$ in Superblock containing a 1:200 concentration of OTR primary antibody (catalog \#sc-8102, Santa Cruz Biotechnology), washed for $60 \mathrm{~min}$ at $23^{\circ} \mathrm{C}$ in $1 \times$ TBS with TBS-T, incubated for $1 \mathrm{~h}$ at a 1:40,000 concentration of donkey anti-goat peroxidase-labeled secondary antibody (catalog \#sc-2033, Santa Cruz Biotechnology), and then washed for $1 \mathrm{~h}$ in TBS-T. All bands were visualized by Super Signal West Dura-enhanced chemiluminescence (catalog \#34706, Pierce). OTR-immunoreactive (ir) bands were visualized at a molecular weight of $66 \mathrm{kDa}$, D1R-ir bands at $74 \mathrm{kDa}$ and D2R-ir) bands at $51 \mathrm{kDa}$. To verify the specificity of these bands, we completed three negative-control experiments for each primary antibody. Western blotting was completed as described, with one of the following exceptions: (1) the target peptide (i.e., OTR, D1R, or D2R), at 10× the concentration of the primary antibody, was added during overnight incubation with the primary antibody; (2) overnight incubation was completed without the primary antibody; and (3) $1 \mathrm{~h}$ incubation was completed without the secondary antibody. In each condition, the target band was not visualized.

Microdialysis probe implantation and dialysate sampling. Concentric style microdialysis probes were constructed as previously described (Curtis et al., 2003), except the active area was $1.0 \mathrm{~mm}$ and the molecular weight cutoff of the membrane was $18 \mathrm{kDa}$. Subjects were anesthetized, and probes were stereotaxically implanted into the right NAcc (coordinates from bregma: anterior, $2.1 \mathrm{~mm}$; lateral, $-0.6 \mathrm{~mm}$; ventral, $6.3 \mathrm{~mm}$ ) and perfused continuously at a rate of $1.5 \mu \mathrm{l} / \mathrm{min}$ with a solution isotonic for $\mathrm{K}, \mathrm{Na}, \mathrm{Mg}$, and $\mathrm{Ca}\left(2.8 \mathrm{~mm} \mathrm{KCl}, 144 \mathrm{~mm} \mathrm{NaCl}, 0.9 \mathrm{~mm} \mathrm{MgCl}_{2}\right.$, and 1.2 $\mathrm{mM} \mathrm{CaCl}_{2}$; Sved and Curtis, 1993). The next morning at 9:00 A.M., four 20 min baseline samples were collected. A male was introduced into the cage and allowed to freely interact with the subject while dialysate samples were collected at $20 \mathrm{~min}$ intervals for $6 \mathrm{~h}$. All samples were collected into vials containing $5 \mu \mathrm{l}$ of $0.1 \mathrm{~N}$ perchloric acid. Males were removed, dye was infused through the probe, and subjects were rapidly decapitated; their brains were then collected, immediately frozen on dry ice, and stored at $-80^{\circ} \mathrm{C}$ for histological verification of the sampling site. Behavioral interactions were videotaped, and the sampling periods during which mating occurred were identified.

HPLC with electrochemical detection. DA levels in dialysates were measured with an ESA CoulArray Model 4600 HPLC system with electrochemical detection (ECD) equipped with a C18 column (ESA; $150 \mathrm{~mm}$, $120 \AA$ ), a $20 \mu \mathrm{lloop}$ (Rheodyne), and a column heater (Eppendorf) held at $29^{\circ} \mathrm{C}$. The flow rate was set at $500 \mu \mathrm{l} / \mathrm{min}$. The mobile phase was composed of 15\% acetonitrile (HPLC grade; Fisher Scientific), 15\% methanol (HPLC grade; Fisher Scientific), $75 \mathrm{~mm} \mathrm{NaH}_{2} \mathrm{PO}_{4}$, and $1.5 \mathrm{~mm}$ SDS, pH 5.14. The electrodes were set at 100, 425, 530, and $650 \mathrm{mV}$. DA was detected in the $100 \mathrm{mV}$ channel. Extracellular DA concentration was determined by comparison with a linear curve generated using $1,5,10$, and $50 \mathrm{~nm}$ DA standards in $0.1 \mathrm{~m}$ perchloric acid. For tissue samples, DA was extracted as previously described (Aragona et al., 2002), except that tissue samples were sonicated in $30 \mu \mathrm{l}$ of $0.1 \mathrm{~m}$ perchloric acid with $0.02 \%$ EDTA. DA concentration was assessed using HPLC-ECD, as described 

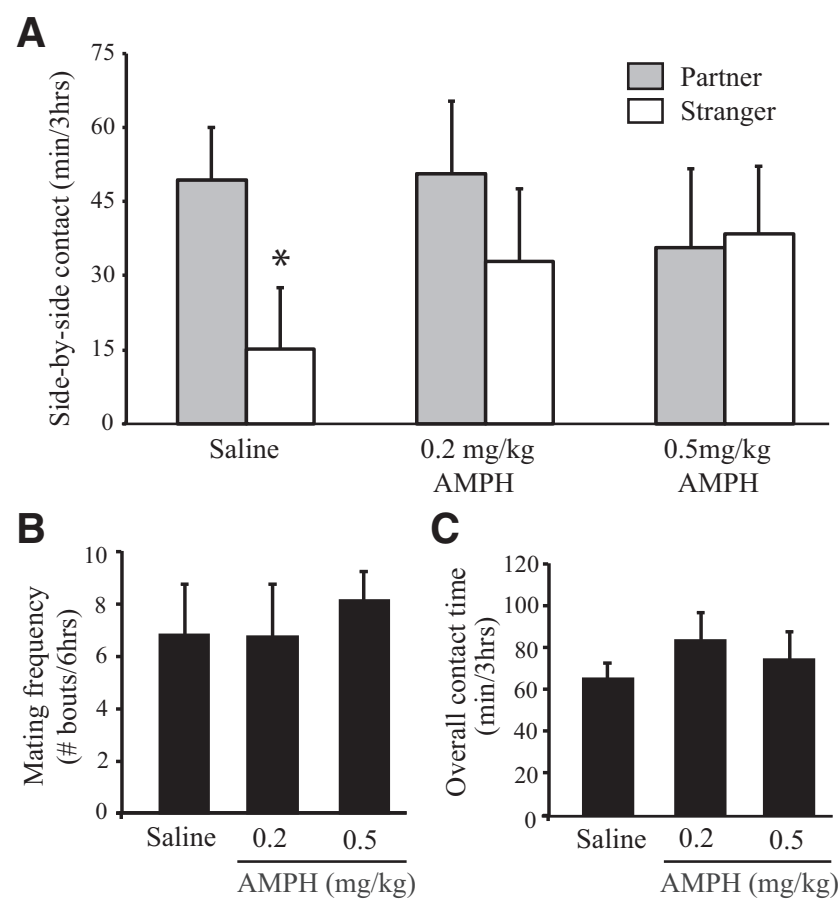

C

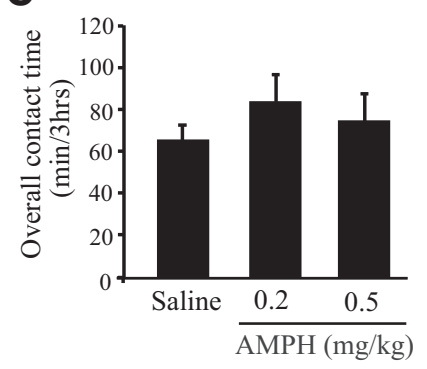

Figure 1. Repeated AMPH treatment impairs mating-induced PP formation in female prairie voles. $\boldsymbol{A}$, Following $24 \mathrm{~h}$ of cohabitation, saline-treated female prairie voles displayed PP (i.e., spent significantly more time in side-by-side contact with the familiar mate vs a strange male). However, AMPH-treated females did not. $\boldsymbol{B}, \boldsymbol{C}$, No group differences were found in the frequency of mating bouts during cohabitation $(\boldsymbol{B})$ or overall contact time during the PP test (C). Error bars indicate the SEM. ${ }^{*} p \leq 0.017$.

previously (Curtis et al., 2003) with the following exceptions. The mobile phase consisted of $75 \mathrm{~mm}$ sodium dihydrogen phosphate monohydrate, $1.7 \mathrm{~mm} 1$-octanesulfonic acid sodium salt, $0.01 \%$ triethylamine, $25 \mu \mathrm{m}$ EDTA, and 7\% acetonitrile, and the $\mathrm{pH}$ was adjusted to 3.0 with $85 \%$ phosphoric acid. The flow rate was $0.5 \mathrm{ml} / \mathrm{min}$. The standard curve and peak area were calculated as described previously (Aragona et al., 2003). The detection limit was $\sim 10 \mathrm{pg} / \mathrm{sample}$.

Stereotaxic cannulation and microinjection. Twenty-six-gauge bilateral guide cannulae (Plastics One) were stereotaxically implanted in anesthetized subjects, aimed at the PLC (coordinates from bregma: anterior, 2.2 $\mathrm{mm}$; bilateral, $\pm 0.5 \mathrm{~mm}$; ventral, $2.5 \mathrm{~mm}$ ). After a $3 \mathrm{~d}$ recovery, microinjections (200 nl/side) of CSF, CSF containing OT, or CSF containing OT plus OTA were made into the PLC. All microinjections were made with a 33-gauge needle that extended $1 \mathrm{~mm}$ below the guide cannulae and were delivered at a rate of $0.2 \mu \mathrm{l} / \mathrm{min}$, as previously described (Aragona et al., 2003).

Data quantification and statistical analysis. For PP tests, the durations of time spent by the subject in side-by-side contact with the partner and stranger were quantified by an experimenter who was blind to treatment and were compared using $t$ tests with Bonferroni correction for multiple comparisons (given that three groups were examined in Experiment 1, and four groups were examined in Experiment 4, the $\alpha$-levels were set at $p \leq 0.017$ and $p \leq 0.0125$, respectively). Group differences in the number of mating bouts during the first $6 \mathrm{~h}$ of cohabitation and overall contact time (i.e., summed time spent in side-by-side contact with both stimulus animals; an index of general affiliation) during the PP test were assessed using a one-way ANOVA. Subjects that failed to mate during the cohabitation period or had misplaced cannulae were excluded from analysis. For the Western blot experiment, optical densities of protein labeling on $\mathrm{x}$-ray film were quantified using a computerized image program (ImageJ, National Institutes of Health). $\beta$-Actin was used to normalize for band intensities, and group differences in normalized OTR-ir, D1R-ir, and D2R-ir densities were analyzed for each brain region using paired $t$ tests with Bonferroni correction for multiple comparisons. For the microdialysis experiment, DA concentrations in the first two samples collected during/after the first mating bout of each subject were averaged to yield one mating value (all animals began mating within the first $40 \mathrm{~min}$ ). A mixed-model ANOVA was used to determine the effects of treatment (between-subjects effect; AMPH vs saline) and sample type (withinsubjects effect; baseline vs mating) on DA concentration. In the tissue punch experiment, DA concentration in each sample was normalized for total protein concentration. A two-way ANOVA was used to determine the effects of treatment (CSF or OT) and sample type (baseline or mated) on group means for DA content in the NAcc. For mated groups, mating bouts were quantified by an experimenter who was blind to treatment, and group differences were compared using a $t$ test. The $\alpha$-level for all analyses was set at $p \leq 0.05$, unless noted above.

\section{Results}

Experiment 1: repeated AMPH exposure impairs matinginduced PP formation

Experiment 1 was designed to test the hypothesis that repeated AMPH exposure inhibits mating-induced PP formation, a reliable behavioral index of pair bond formation (Insel and Hulihan, $1995)$ in female prairie voles. Subjects were randomly divided into three groups that received one injection of $\mathrm{EB}$ - to induce sexual receptivity (Gingrich et al., 2000) — and one injection of $0.9 \%$ saline $(n=16), 0.2 \mathrm{mg} / \mathrm{kg}$ AMPH $(n=7)$, or $0.5 \mathrm{mg} / \mathrm{kg}$ AMPH $(n=8)$ at the same time (9:00 A.M.) each day for 3 consecutive days. Twenty-four hours after the final set of injections, subjects were paired with a male for a $24 \mathrm{~h}$ period of cohabitation and were then tested for PP.

Saline-treated females formed PPs, as they spent significantly more time in side-by-side contact with their familiar partner than the stranger animal $\left(t_{(30)}=2.95, p=0.006\right.$; Fig. $\left.1 A\right)$. Females treated with either dose of AMPH did not form PPs, but instead demonstrated nonselective side-by-side contact with the stimulus males during the PP test (Fig. 1A). No differences were found in mating frequency during the cohabitation period (Fig. $1 B$ ) or overall contact time (Fig. $1 C$ ) during the PP test. Together, these data indicate that repeated AMPH exposure impairs PP formation in female prairie voles, and that this effect is not due to AMPH-induced alterations in mating frequency or general affiliative behavior.

\section{Experiment 2: repeated AMPH exposure decreases mPFC OTR-ir and NAcc D2R-ir densities}

OTR and DAR activation in mesocorticolimbic brain regions mediate PP formation in female prairie voles (Gingrich et al., 2000; Young et al., 2001; Liu and Wang, 2003). Since AMPH exposure inhibited PP formation in Experiment 1, Experiment 2 was designed to test the hypothesis that repeated AMPH exposure alters OTR and/or DAR densities in the NAcc, mPFC, and/or VTA (Fig. 2A). Given that the DA regulation of PP formation is receptor specific $-\mathrm{D}_{2}$-like receptor activation facilitates, whereas $\mathrm{D}_{1}$-like receptor activation prevents PP (Gingrich et al., 2000; Aragona et al., 2006)—we examined the densities of both receptor subtypes. Subjects were randomly divided into two groups that received injections of EB or EB plus $0.2 \mathrm{mg} / \mathrm{kg} \mathrm{AMPH}(n=$ 6-8 per group, depending on the receptor and brain region tested), once per day for 3 consecutive days. EB was used as a control manipulation because all subjects in Experiment 1 received EB to induce sexual receptivity. Twenty-four hours after the final injections (the critical time point at which subjects were paired with a conspecific in Experiment 1), subjects were rapidly decapitated. All brains were harvested, frozen on dry ice, and stored at $-80^{\circ} \mathrm{C}$ until processed for Western blotting.

AMPH-treated females had significantly lower OTR-ir levels in the $\operatorname{mPFC}\left(t_{(6)}=4.82, p=0.003\right)$, but not in the NAcc or VTA, than EB-treated controls (Fig. 2B). AMPH-treated females also 
A

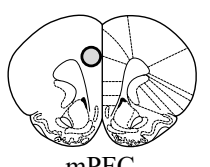

$\mathrm{mPFC}$

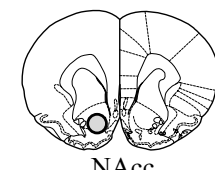

NAcc

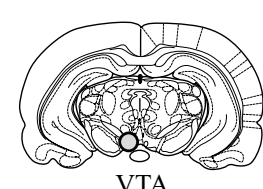

VTA
B

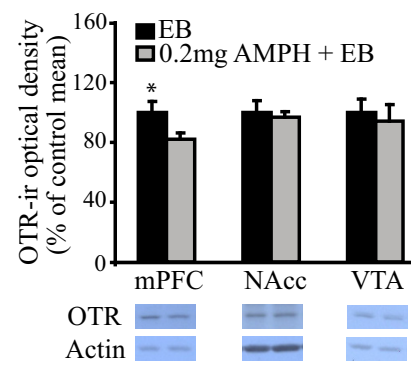

C

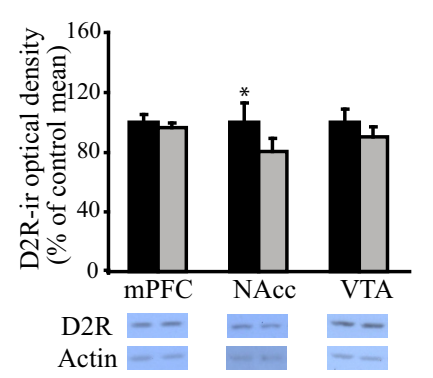

Figure 2. Repeated AMPH treatment alters mesocorticolimbic OTR and DA D2R immunoreactivity in female prairie voles. $A$, Schematic drawing illustrating tissue punch locations in the mPFC, NAcc, and VTA. $B$, OTR-ir was significantly lower in the mPFC of AMPH-treated, than EB-treated control, females. No group differences were noted in OTR-ir in the NAcc or VTA. $C$, D2R-ir was significantly lower in the NAcc, but not in the MPFC or VTA, of AMPH-treated, compared with EB-treated control, females. Error bars indicate the SEM. ${ }^{*} p \leq 0.017$.

had significantly lower D2R-ir levels in the NAcc than EB-treated controls $\left(t_{(5)}=3.68, p=0.014\right.$; Fig. $\left.2 C\right)$. No group differences were noted in D2R-ir density in the mPFC or VTA (Fig. 2C) or in D1R-ir density in any region tested. As AMPH treatment decreased OTR-ir density in the mPFC and D2R-ir density in the NAcc, but not in the other brain regions examined, and had no effects on D1R-ir density, these results indicate that the effects of AMPH on OTR and DAR expression are site and receptor specific.

\section{Experiment 3: repeated AMPH exposure increases extracellular levels of NAcc DA}

As mating-induced NAcc DA release facilitates PP formation in female prairie voles (Gingrich et al., 2000), Experiment 3 was designed to test the hypothesis that repeated AMPH exposure alters baseline and/or mating-induced NAcc DA levels. Importantly, we examined NAcc DA levels $24 \mathrm{~h}$ after the cessation of treatment, which, again, is the critical time point at which subjects were paired with a conspecific in Experiment 1. Subjects received one injection of $\mathrm{EB}$ and one injection of either saline $(n=6)$ or $0.2 \mathrm{mg} / \mathrm{kg}$ AMPH $(n=7)$ each day for 3 consecutive days. Five hours following the final set of injections, microdialysis probes were implanted into the NAcc, and subjects were allowed to recover overnight while an isotonic salt solution was perfused continuously through the probe. The next morning, four $20 \mathrm{~min}$ baseline dialysate samples were collected. Thereafter, a male was placed into the cage with the subject and the animals were allowed to freely interact while dialysate samples were collected every $20 \mathrm{~min}$. Baseline samples and the two samples collected during/after the first mating bout of each subject were subsequently analyzed for DA content using HPLC-ECD analysis.

A main effect of treatment was found $\left(F_{(1,11)}=4.65 ; p=\right.$ $0.05)$, such that AMPH-treated subjects had a significantly higher concentration of extracellular DA in the NAcc than did salinetreated subjects (Fig. 3). Additionally, a main effect of sample type was found $\left(F_{(1,11)}=26.24, p=0.0003\right)$, such that samples collected during/after mating had a significantly higher concentration of DA than baseline samples. There was also a nonsignif-

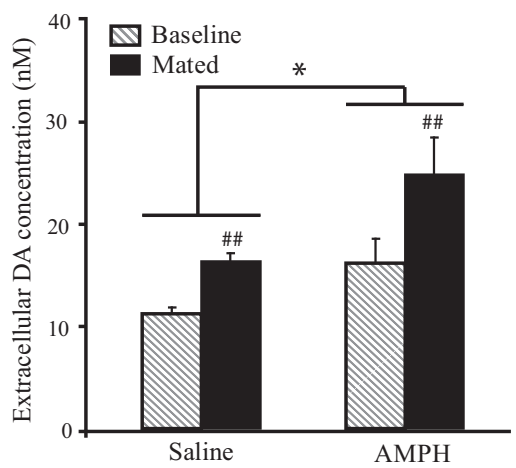

Figure 3. Subjects treated with AMPH had significantly higher levels of extracellular DA in the NAcc than those treated with saline. Additionally, samples collected during mating contained significantly more DA than baseline samples. Error bars indicate the SEM. ${ }^{*} p \leq 0.05$, main effect of treatment; \#\#p $\leq 0.001$, main effect of sample type.

icant trend for an interaction effect $\left(F_{(1,11)}=4.21, p=0.065\right)$, driven by greater mating-induced DA levels in AMPH-treated subjects compared with saline-treated subjects. These data demonstrate that repeated AMPH administration elevated extracellular levels of DA in the NAcc $24 \mathrm{~h}$ after the cessation of AMPH treatment.

\section{Experiment 4: OT infusion into the PLC restores mating-} induced $\mathrm{PP}$ formation in $\mathrm{AMPH}$-exposed females

Since AMPH treatment reduced OTR-ir density in the mPFC (Experiment 2), and OTR activation in the PLC-a subregion of the $\mathrm{MPFC}$ - is necessary for the formation of PP in female prairie voles (Young et al., 2001), we hypothesized that decreased PLC OT neurotransmission may be involved in the AMPH-induced impairment of PP. Therefore, we tested whether direct infusion of OT into the PLC restores mating-induced PP formation in AMPH-treated females. Subjects were implanted with guide cannulae bilaterally aimed at the PLC. After a $3 \mathrm{~d}$ recovery, all subjects received one injection of $\mathrm{EB}$ and one injection of $0.2 \mathrm{mg} / \mathrm{kg}$ AMPH each day for 3 consecutive days. Twenty-four hours after the final injections, subjects were randomly divided into four groups that received an intra-PLC injection (Fig. 4A) of CSF ( $n=$ $8), 1 \mathrm{ng}$ of OT ( $n=8), 1 \mathrm{ng}$ of OT plus $10 \mathrm{ng}(n=11)$ or $200 \mathrm{ng}$ $(n=5)$ of OTA, were immediately paired with a male for a $24 \mathrm{~h}$ period of cohabitation and mating, and were then tested for PP.

Consistent with our finding that repeated AMPH exposure impairs PP formation (Experiment 1), CSF-treated females failed to form mating-induced PPs (i.e., spent similar amounts of time in side-by-side contact with both stimulus animals; Fig. 4B). OTtreated females, however, formed robust PPs $\left(t_{(14)}=6.75, p=\right.$ 0.000009), while subjects treated with OT plus either dose of OTA did not (Fig. 4B). No differences were found between treatment groups in the number of mating bouts during the cohabitation period (Fig. 4C) or in the overall contact time during the PP test (Fig. 4C). Together, these data indicate that OT infusion into the PLC restores mating-induced PP formation in AMPH-treated females through an OTR-mediated mechanism.

\section{Experiment 5: PLC OT infusion alters DA concentration in} the NAcc

Since pharmacological manipulations in the PLC have the potential to alter DA transmission in the NAcc (Tzschentke, 2001), Experiment 5 was designed to test the hypothesis that OT infusion into the PLC alters DA concentration in the NAcc of AMPHtreated voles. All subjects were implanted with guide cannulae 
A

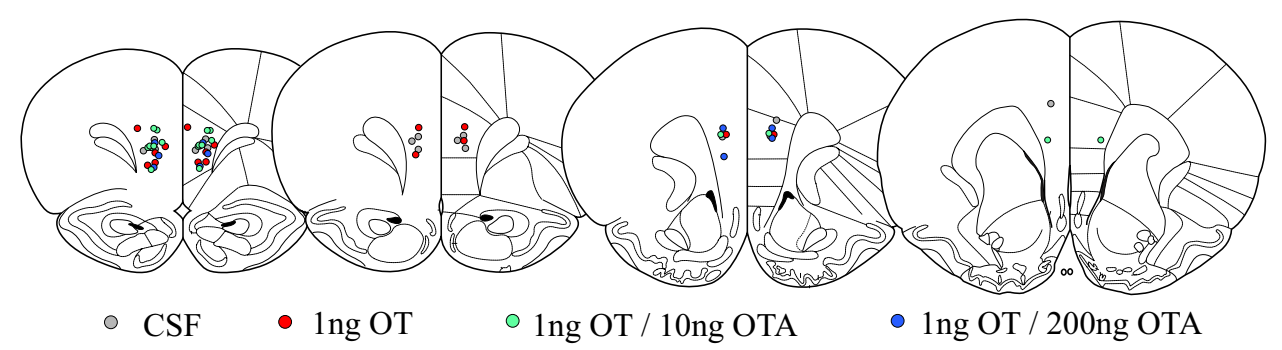

B
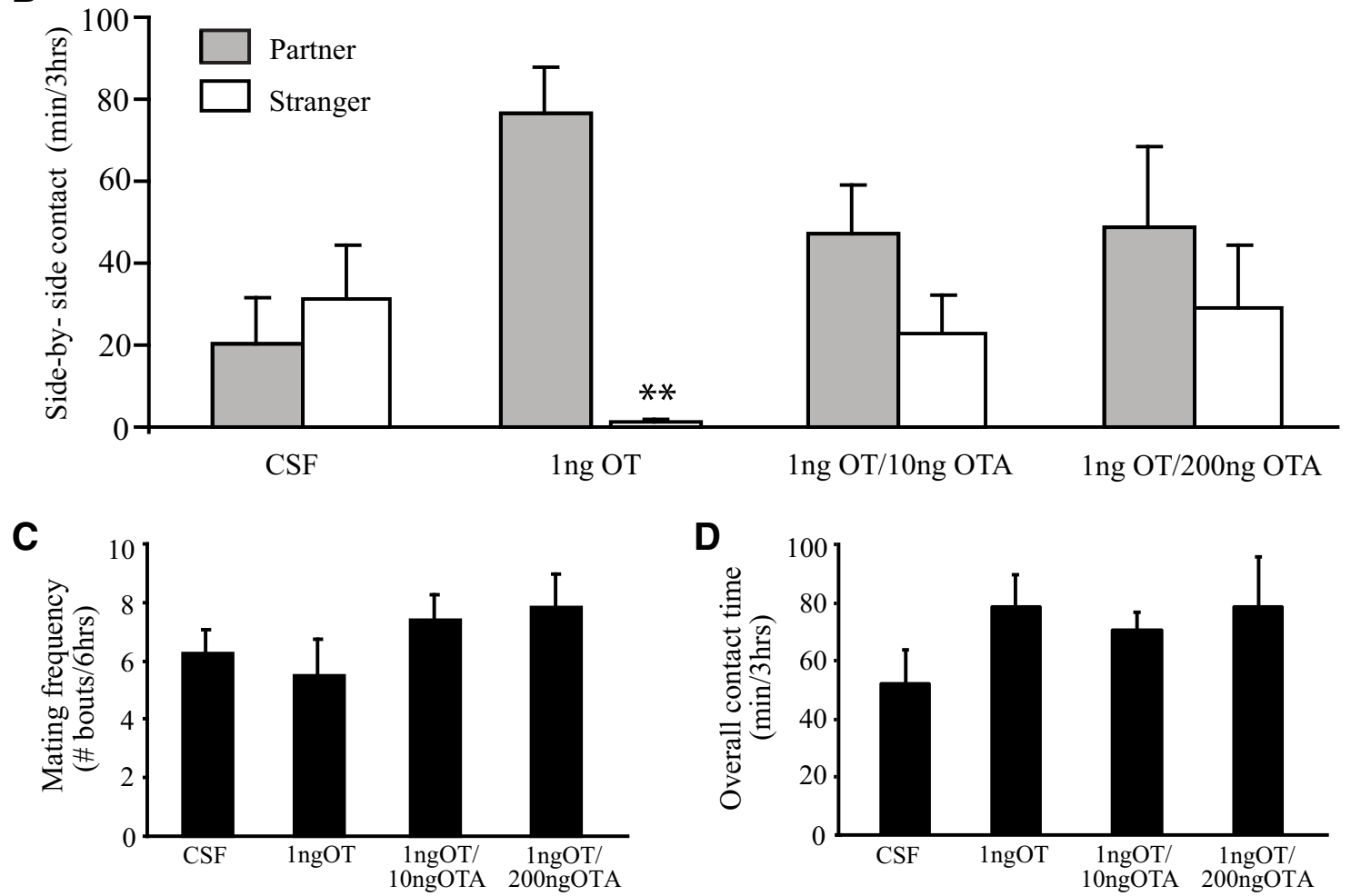

Figure 4. OT infusion into the PLC restores mating-induced PP formation in AMPH-treated females. $\boldsymbol{A}$, Schematic drawing illustrating the location of OT microinjections for all subjects. $\boldsymbol{B}$, Subjects that received artificial CSF into the PLC did not form PPs. However, subjects treated with OT formed robust PPs. The effects of OT on PP formation were blocked by simultaneous administration of an OTA. $\boldsymbol{C}, \boldsymbol{D}$, No group differences were found in the frequency of mating bouts during cohabitation $(\boldsymbol{C})$ or the overall contact time during the PP test (D). Error bars indicate the SEM. ${ }^{* *} p \leq 0.0125$.

aimed bilaterally at the PLC and were allowed to recover for $3 \mathrm{~d}$. Subjects then received one injection of EB and $0.2 \mathrm{mg} / \mathrm{kg} \mathrm{AMPH}$ each day for 3 consecutive days. Twenty-four hours following the final injections, subjects were randomly divided into one of two groups that received an intra-PLC injection of either CSF or CSF containing $1 \mathrm{ng}$ of OT. Each group was further divided into two subgroups that were either left undisturbed for $40 \mathrm{~min}$ and then killed (baseline group; $n=7 \mathrm{CSF}, n=8 \mathrm{OT}$ ) or were paired with a male, allowed to mate, and killed $40 \mathrm{~min}$ after the completion of their first mating bout (mated group; $n=7 \mathrm{CSF}, n=7 \mathrm{OT}$ ). Tissue punches from the NAcc of each animal were analyzed for DA concentration using HPLC-ECD.

A main effect of treatment was found $\left(F_{(1,25)}=4.37 ; p=\right.$ 0.047 ) on NAcc DA concentration, such that subjects treated with OT had a significantly higher concentration of DA in the NAcc than those treated with CSF (Fig. 5). There was also a main effect of sociosexual experience $\left(F_{(1,25)}=14.27 ; p<0.001\right)$ on DA concentration. Specifically, subjects in the mated group had a significantly lower concentration of DA in the NAcc than those in the baseline group (Fig. 5). No differences were found in the total number of mating bouts between CSF- and OT-treated subjects in the mated group. These data demonstrate that PLC OT treat- ment alters DA concentration in the NAcc of AMPH-treated voles.

\section{Discussion}

In this study, we investigated the neural mechanisms that underlie the drug-induced impairment of pair bonding and its treatment with OT in female prairie voles. We demonstrate that repeated exposure to a commonly abused drug, AMPH, impairs PP formation (Experiment 1) - a reliable index of pair bonding - and alters OT and DA neurotransmission in the MPFC and NAcc, respectively (Experiments 2 and 3). Additionally, we demonstrate that OT infusion into the PLC restores PP formation in AMPH-treated females (Experiment 4), and we provide evidence that OT may have this effect through an interaction with NAcc DA (Experiment 5). Collectively, these results support our hypothesis that alterations in mesocorticolimbic OT and DA neurotransmission underlie the impairment of social bonding in female voles and demonstrate that treatment with the endogenous neuropeptide OT restores normal bonding behavior in drug-treated animals.

Previous studies in our laboratory and others have demonstrated that $24 \mathrm{~h}$ of sociosexual experience with a male reliably 


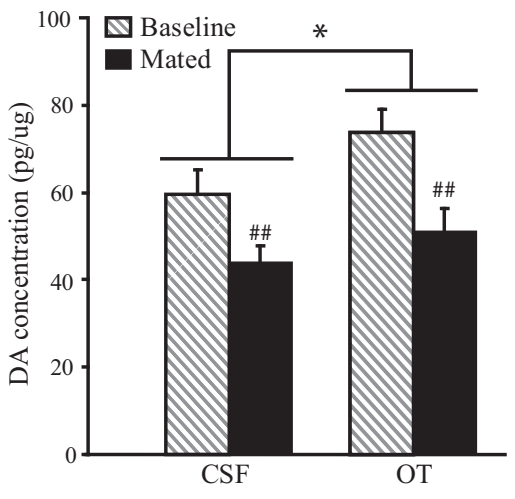

Figure 5. Subjects that received $\mathrm{OT}$ infusions into the PLC had a significantly higher concentration of DA in the NAcc than did subjects treated with artificial CSF. Additionally, subjects paired with a male and allowed to mate (Mated) had a significantly lower concentration of DA in the NAcc than subjects not paired with a male (Baseline). Error bars indicate the SEM. ${ }^{*} p \leq$ 0.05 , main effect of treatment; \#\# $\leq 0.001$, main effect of sample type.

induces PP formation in female prairie voles (Williams et al., 1992; Insel and Hulihan, 1995). Here, we show that prior experience with AMPH inhibits the formation of these selective preferences. These effects are not likely due to the acute actions of AMPH on brain and behavior, as PP tests were performed $48 \mathrm{~h}$ after the final AMPH exposure (e.g., after the drug had been metabolized), or to behavioral deficits induced by an aversive state of AMPH withdrawal, as no effects on mating frequency during the cohabitation period or general affiliative behavior during the partner preference test were noted (Fig. 1). Our finding that prior exposure to AMPH impairs PP formation in female prairie voles is consistent with the effects of this drug in males of this species (Liu et al., 2010) and the enduring effects of repeated psychostimulant exposure on other prosocial behaviors (Clemens et al., 2007), including maternal behavior (Johns et al., 1997a; Slamberová et al., 2005; but see, Febo and Ferris, 2007) and social play (Wood et al., 1994).

AMPH dosing sufficient to impair PP formation decreased OTR-ir density in the MPFC, but did not alter OTR-ir levels in the NAcc or VTA (Fig. 2) - findings consistent with other studies that have documented region-specific effects of psychostimulants on markers of OT function (Sarnyai et al., 1992; Johns et al., 2010). These changes were present $24 \mathrm{~h}$ after the final AMPH injection-the critical time point at which AMPH-treated females were paired with a male, and allowed to cohabitate and mate before being tested for PP. Importantly, OTR activation in the mPFC, specifically the PLC, during cohabitation and mating is necessary for PP formation in female prairie voles (Young et al., 2001). Therefore, decreased OTR activation in the PLC at this time point may represent a potential neural mechanism by which AMPH impairs mating-induced PP formation. In support of this hypothesis, OT injection directly into the PLC, immediately before pairing, restored mating-induced PP formation in AMPHtreated subjects, and this effect was dependent on PLC OTR activation (Fig. 4). Together, these data indicate that AMPHinduced decreases in PLC OTR expression may, in part, underlie the inhibitory effects of this drug on PP formation. This finding is in line with studies indicating that regional variations in central OTR expression mediate species and individual differences in social behaviors (Francis et al., 2000; Olazábal and Young, 2006), including pair bonding (Ross et al., 2009a; Ophir et al., 2012). It is worth mentioning that several classic controls were included in the Western blotting experiment, which clearly indicated that our antibodies were specific to our receptors of interest. However, these controls may not completely rule out the possibility that the antibodies used could bind to other unknown proteins with similar molecular weights and antigen-binding sites.

Our results also indicate that alterations in NAcc DA neurotransmission may contribute to the AMPH-induced impairment of PP formation in females, extending our previous findings in males (Liu et al., 2010). NAcc DA mediates PP formation in a receptor-specific manner- $\mathrm{D}_{2}$-like receptor activation facilitates, whereas $\mathrm{D}_{1}$-like receptor activation inhibits, PP formation (Gingrich et al., 2000; Aragona et al., 2006). In the current study, AMPH dosing decreased NAcc D2R-ir density (Fig. 2), yet did not alter D1R-ir density, indicating a potential increase in the ratio of D1R to D2R in this region. Additionally, AMPH exposure increased extracellular DA levels in the NAcc (Fig. 3). Together, these results not only indicate a decreased likelihood of D2R activation by released DA, but also an increased likelihood of D1R activation. Indeed, DA has a differential affinity for different DA receptor subtypes, and higher levels of extracellular DA are required to activate D1Rs (Richfield et al., 1989). Given the NAcc DA receptor-specific regulation of $\mathrm{PP}$ formation (Gingrich et al., 2000; Aragona et al., 2006), these data collectively indicate that AMPH may impair pair bond formation in female prairie voles by shifting the balance of NAcc DA receptor activation in favor of D1Rs_-paralleling our previous results in males (Liu et al., 2010).

The decrease in NAcc D2R-ir density noted here, and its relationship to the AMPH-induced impairment of pair bonding, warrants further discussion. NAcc D2R activation is thought to facilitate partner preference formation by enhancing reward processing during sociosexual experience with a mate (for review, see Aragona and Wang, 2009). Indeed, reduced activation of NAcc neurons - a consequence of $\mathrm{D}_{2}$-like receptor activation (Surmeier et al., 2007) - is critically involved in the processing of reward states (for review, see Carlezon and Thomas, 2009). AMPH-induced decreases in NAcc D2R-ir density may therefore be indicative of impaired reward processing during sociosexual interactions. Although this idea was not tested here, it parallels clinical work demonstrating reductions in $\mathrm{NAcc}_{2}$-like receptor availability following long-term drug exposure and suggesting that such neuroadaptations may decrease the sensitivity to natural rewards in addicted individuals (Volkow et al., 2007).

A major finding in the current study, as discussed previously, is that OT administered directly into the PLC restored pair bond formation in AMPH-treated voles. Importantly, PLC OT treatment also altered NAcc DA tissue concentration: AMPH-treated subjects that received OT had a significantly higher concentration of DA in NAcc tissue than did subjects that received CSF (Fig. 5). This effect could be the result of OT-induced increases in DA synthesis or decreases in DA release. The latter possibility is particularly intriguing, as it would indicate that OT administration counteracts AMPH-induced increases in extracellular NAcc DA levels. Unfortunately, this possibility could not be tested directly here, as the small size of the vole brain precluded the simultaneous implantation of guide cannulae and a microdialysis probe into the PLC and NAcc, respectively. Nevertheless, the idea that PLC OT injection may alter NAcc DA release is consistent with studies demonstrating the physical and functional connectivity of these regions within the mesocorticolimbic circuit. For example, the PLC contains a high density of pyramidal cells that project to the VTA (Carr and Sesack, 1999) and through this anatomical connection is thought to influence NAcc DA neurotransmission. Indeed, chemical or electrical stimulation of the $\mathrm{mPFC}$ increases, while temporary $\mathrm{mPFC}$ inactivation decreases, 
the firing rate and burst events of DA neurons in the VTA, and these events are thought to directly account for related increases/ decreases in extracellular NAcc DA (for review, see Tzschentke, 2001). Therefore, pharmacological manipulations within the PLC (e.g., OT injection) have the potential to alter NAcc DA release. Although this possibility could not be tested in the current study, our data demonstrate that $\mathrm{OT}$ administration alters NAcc DA levels in AMPH-treated voles-suggesting that OT-DA interactions may be involved in the OT-induced restoration of social bonding.

Given the critical role of central OT in the regulation of social behaviors (Ross and Young, 2009), alterations in this system have been hypothesized to underlie social deficits in a number of psychiatric disorders, including drug addiction (McGregor et al., 2008). It has therefore been suggested that the OT system may represent a viable pharmacotherapeutic target for the treatment of social deficits in addiction (Strathearn and Mayes, 2010; McGregor and Bowen, 2012). Here, we provide empirical evidence to support these ideas. Perhaps most intriguing is our finding that OT administration restores social bonding in drug-exposed animals. Together with emerging evidence that the role of OT in social behavior is largely conserved across species (Ross and Young, 2009; Meyer-Lindenberg et al., 2011; Burkett and Young, 2012) and that OT systems are altered in human drug users (Light et al., 2004), these results support the utility of the OT system as a neural target for the pharmacological treatment of social deficits in addiction. However, additional studies are required to determine the translational potential of these findings to primate species with increasingly complex social relationships, including our own. Continued research on these topics would not only allow for the confirmation of this system as a neural target for the treatment of social deficits in addiction, but could also significantly impact the treatment of addiction itself-as strong social bonds may play an important role in relapse prevention (Kosten et al., 1987; Dawson et al., 2005).

\section{References}

Aragona BJ, Wang Z (2009) Dopamine regulation of social choice in a monogamous rodent species. Front Behav Neurosci 3:15. CrossRef Medline

Aragona BJ, Curtis JT, Davidson AJ, Wang Z, Stephan FK (2002) Behavioral and neurochemical investigation of circadian time-place learning in the rat. J Biol Rhythms 17:330-344. CrossRef Medline

Aragona BJ, Liu Y, Curtis JT, Stephan FK, Wang Z (2003) A critical role for nucleus accumbens dopamine in partner-preference formation in male prairie voles. J Neurosci 23:3483-3490. Medline

Aragona BJ, Liu Y, Yu YJ, Curtis JT, Detwiler JM, Insel TR, Wang Z (2006) Nucleus accumbens dopamine differentially mediates the formation and maintenance of monogamous pair bonds. Nat Neurosci 9:133-139. CrossRef Medline

Bosch OJ, Neumann ID (2012) Both oxytocin and vasopressin are mediators of maternal care and aggression in rodents: from central release to sites of action. Horm Behav 61:293-303. CrossRef Medline

Burkett JP, Young LJ (2012) The behavioral, anatomical and pharmacological parallels between social attachment, love and addiction. Psychopharmacology 224:1-26. CrossRef Medline

Butovsky E, Juknat A, Elbaz J, Shabat-Simon M, Eilam R, Zangen A, Altstein M, Vogel Z (2006) Chronic exposure to Delta9-tetrahydrocannabinol downregulates oxytocin and oxytocin-associated neurophysin in specific brain areas. Mol Cell Neurosci 31:795-804. CrossRef Medline

Carlezon WA Jr, Thomas MJ (2009) Biological substrates of reward and aversion: a nucleus accumbens activity hypothesis. Neuropharmacology 56 [Suppl 1]:122-132. CrossRef Medline

Carr DB, Sesack SR (1999) Terminals from the rat prefrontal cortex synapse on mesoaccumbens VTA neurons. Ann N Y Acad Sci 877:676-678. CrossRef Medline

Clemens KJ, Van Nieuwenhuyzen PS, Li KM, Cornish JL, Hunt GE, McGregor IS (2004) MDMA ("ecstasy"), methamphetamine and their combination: long-term changes in social interaction and neurochemistry in the rat. Psychopharmacology 173:318-325. CrossRef Medline

Clemens KJ, Cornish JL, Hunt GE, McGregor IS (2007) Repeated weekly exposure to MDMA, methamphetamine or their combination: long-term behavioural and neurochemical effects in rats. Drug Alcohol Depend 86: 183-190. CrossRef Medline

Collins RL, Ellickson PL, Klein DJ (2007) The role of substance use in young adult divorce. Addiction 102:786-794. CrossRef Medline

Curtis JT, Stowe JR, Wang Z (2003) Differential effects of intraspecific interactions on the striatal dopamine system in social and non-social voles. Neuroscience 118:1165-1173. CrossRef Medline

Dawson DA, Grant BF, Stinson FS, Chou PS, Huang B, Ruan WJ (2005) Recovery from DSM-IV alcohol dependence: United States, 2001-2002. Addiction 100:281-292. CrossRef Medline

Febo M, Ferris CF (2007) Development of cocaine sensitization before pregnancy affects subsequent maternal retrieval of pups and prefrontal cortical activity during nursing. Neuroscience 148:400-412. CrossRef Medline

Francis DD, Champagne FC, Meaney MJ (2000) Variations in maternal behaviour are associated with differences in oxytocin receptor levels in the rat. J Neuroendocrinol 12:1145-1148. Medline

Gingrich B, Liu Y, Cascio C, Wang Z, Insel TR (2000) Dopamine D2 receptors in the nucleus accumbens are important for social attachment in female prairie voles (Microtus ochrogaster). Behav Neurosci 114:173183. CrossRef Medline

Henry DJ, Greene MA, White FJ (1989) Electrophysiological effects of cocaine in the mesoaccumbens dopamine system: repeated administration. J Pharmacol Exp Ther 251:833-839. Medline

House JS, Landis KR, Umberson D (1988) Social relationships and health. Science 241:540-545. CrossRef Medline

Insel TR, Hulihan TJ (1995) A gender-specific mechanism for pair bonding: oxytocin and partner preference formation in monogamous voles. Behav Neurosci 109:782-789. CrossRef Medline

Johns JM, Noonan LR, Zimmerman LI, Li L, Pedersen CA (1997a) Effects of short- and long-term withdrawal from gestational cocaine treatment on maternal behavior and aggression in Sprague-Dawley rats. Dev Neurosci 19:368-374. CrossRef Medline

Johns JM, Lubin DA, Walker CH, Meter KE, Mason GA (1997b) Chronic gestational cocaine treatment decreases oxytocin levels in the medial preoptic area, ventral tegmental area and hippocampus in Sprague-Dawley rats. Neuropeptides 31:439-443. CrossRef Medline

Johns JM, McMurray MS, Joyner PW, Jarrett TM, Williams SK, Cox ET, Black MA, Middleton CL, Walker CH (2010) Effects of chronic and intermittent cocaine treatment on dominance, aggression, and oxytocin levels in post-lactational rats. Psychopharmacology (Berl) 211:175-185. CrossRef Medline

Kaestner R (1995) The effects of cocaine and marijuana use on marriage and marital stability. National Bureau of Economic Research Working Paper No. 5038. Cambridge, MA: National Bureau of Economic Research.

Kiecolt-Glaser JK, Newton TL (2001) Marriage and health: his and hers. Psychol Bull 127:472-503. CrossRef Medline

Kosten TR, Jalali B, Steidl JH, Kleber HD (1987) Relationship of marital structure and interactions to opiate abuse relapse. Am J Drug Alcohol Abuse 13:387-399. CrossRef Medline

Light KC, Grewen KM, Amico JA, Boccia M, Brownley KA, Johns JM (2004) Deficits in plasma oxytocin responses and increased negative affect, stress, and blood pressure in mothers with cocaine exposure during pregnancy. Addict Behav 29:1541-1564. CrossRef Medline

Liu Y, Wang ZX (2003) Nucleus accumbens oxytocin and dopamine interact to regulate pair bond formation in female prairie voles. Neuroscience 121:537-544. CrossRef Medline

Liu Y, Aragona BJ, Young KA, Dietz DM, Kabbaj M, Mazei-Robison M, Nestler EJ, Wang Z (2010) Nucleus accumbens dopamine mediates amphetamine-induced impairment of social bonding in a monogamous rodent species. Proc Natl Acad Sci U S A 107:1217-1222. CrossRef Medline

McGregor IS, Bowen MT (2012) Breaking the loop: oxytocin as a potential treatment for drug addiction. Horm Behav 61:331-339. CrossRef Medline

McGregor IS, Callaghan PD, Hunt GE (2008) From ultrasocial to antisocial: a role for oxytocin in the acute reinforcing effects and long-term adverse 
consequences of drug use? Br J Pharmacol 154:358-368. CrossRef Medline

Melis MR, Argiolas A (2011) Central control of penile erection: a revisitation of the role of oxytocin and its interaction with dopamine and glutamic acid in male rats. Neurosci Biobehav Rev 35:939-955. CrossRef Medline

Meyer-Lindenberg A, Domes G, Kirsch P, Heinrichs M (2011) Oxytocin and vasopressin in the human brain: social neuropeptides for translational medicine. Nat Rev Neurosci 12:524-538. CrossRef Medline

Nestler EJ (2005) Is there a common molecular pathway for addiction? Nat Neurosci 8:1445-1449. CrossRef Medline

Olazábal DE, Young LJ (2006) Species and individual differences in juvenile female alloparental care are associated with oxytocin receptor density in the striatum and the lateral septum. Horm Behav 49:681-687. CrossRef Medline

Ophir AG, Gessel A, Zheng DJ, Phelps SM (2012) Oxytocin receptor density is associated with male mating tactics and social monogamy. Horm Behav 61:445-453. CrossRef Medline

Richfield EK, Penney JB, Young AB (1989) Anatomical and affinity state comparisons between dopamine D1 and D2 receptors in the rat central nervous system. Neuroscience 30:767-777. CrossRef Medline

Ross HE, Young LJ (2009) Oxytocin and the neural mechanisms regulating social cognition and affiliative behavior. Front Neuroendocrinol 30:534547. CrossRef Medline

Ross HE, Freeman SM, Spiegel LL, Ren X, Terwilliger EF, Young LJ (2009a) Variation in oxytocin receptor density in the nucleus accumbens has differential effects on affiliative behaviors in monogamous and polygamous voles. J Neurosci 29:1312-1318. CrossRef Medline

Ross HE, Cole CD, Smith Y, Neumann ID, Landgraf R, Murphy AZ, Young LJ (2009b) Characterization of the oxytocin system regulating affiliative behavior in female prairie voles. Neuroscience 162:892-903. CrossRef Medline

Sarnyai Z, Vecsernyés M, Laczi F, Bíró E, Szabó G, Kovács GL (1992) Effects of cocaine on the contents of neurohypophyseal hormones in the plasma and in different brain structures in rats. Neuropeptides 23:27-31. CrossRef Medline

Slamberová R, Charousová P, Pometlová M (2005) Maternal behavior is impaired by methamphetamine administered during pre-mating, gestation and lactation. Reprod Toxicol 20:103-110. CrossRef Medline

Strathearn L, Mayes LC (2010) Cocaine addiction in mothers: potential effects on maternal care and infant development. Ann N Y Acad Sci 1187: 172-183. CrossRef Medline

Surmeier DJ, Ding J, Day M, Wang Z, Shen W (2007) D1 and D2 dopaminereceptor modulation of striatal glutamatergic signaling in striatal medium spiny neurons. Trends Neurosci 30:228-235. CrossRef Medline

Sved AF, Curtis JT (1993) Amino acid neurotransmitters in nucleus tractus solitarius: an in vivo microdialysis study. J Neurochem 61:2089-2098. CrossRef Medline

Tzschentke TM (2001) Pharmacology and behavioral pharmacology of the mesocortical dopamine system. Prog Neurobiol 63:241-320. CrossRef Medline

Volkow ND, Fowler JS, Wang GJ, Swanson JM, Telang F (2007) Dopamine in drug abuse and addiction: results of imaging studies and treatment implications. Arch Neurol 64:1575-1579. CrossRef Medline

Wasserman DR, Leventhal JM (1993) Maltreatment of children born to cocaine-dependent mothers. Am J Dis Child 147:1324-1328. Medline

Williams JR, Carter CS, Insel T (1992) Partner preference development in female prairie voles is facilitated by mating or the central infusion of oxytocin. Ann N Y Acad Sci 652:487-489. CrossRef Medline

Witt DM, Carter CS, Lnsel TR (1991) Oxytocin receptor binding in female prairie voles: endogenous and exogenous oestradiol stimulation. J Neuroendocrinol 3:155-161. CrossRef Medline

Wood RD, Bannoura MD, Johanson IB (1994) Prenatal cocaine exposure: effects on play behavior in the juvenile rat. Neurotoxicol Teratol 16:139 144. CrossRef Medline

Young KA, Gobrogge KL, Wang Z (2011a) The role of mesocorticolimbic dopamine in regulating interactions between drugs of abuse and social behavior. Neurosci Biobehav Rev 35:498-515. CrossRef Medline

Young KA, Gobrogge KL, Liu Y, Wang Z (2011b) The neurobiology of pair bonding: insights from a socially monogamous rodent. Front Neuroendocrinol 32:53-69. CrossRef Medline

Young LJ, Lim MM, Gingrich B, Insel TR (2001) Cellular mechanisms of social attachment. Horm Behav 40:133-138. CrossRef Medline 